\title{
Satellite-image users fear private price hike
}

Tony Reichhardt, Washington

It didn't work then, and it may not work now. That's the message from some globalchange researchers, who fear that privatization of the Landsat satellite system could drive up the price of images of the Earth's surface, just as it did when the service was taken out of public hands in the 1980s.

Landsat satellites have photographed the Earth for 30 years, providing researchers with a valuable record of changes such as deforestation. The current satellite - the seventh in the series - is operated by NASA and the US Geological Survey, but Congress has repeatedly asked for its successor to be privatized. A draft invitation for bids to run the system is expected from NASA in the next few weeks, with the formal version due by the end of the year.

The successful company would have to build and launch a replacement for Landsat 7, which is designed to last at least until 2004, but is expected to operate for several years beyond that. In return, the firm would be paid by the US government to provide a regular supply of images of the Earth. Satellite-imaging companies DigitalGlobe and Resource21, both based in Denver, Colorado, are currently working with NASA on the future of Landsat, and are expected to bid for the contract.

Landsat was privatized in 1985 , but a commercial market for its pictures failed to develop. Left to market forces, researchers ended up paying thousands of dollars for a single image. This inhibited wider scientific use of remote-sensing imagery, according to a 1997 National Academy of Sciences study, and was the reason that the government resumed control of Landsat in 1992. Costs have remained at a subsidized rate of $\$ 600$ per image since Landsat 7's launch in 1999.

The new Landsat contract will require the operator to supply the government with images of 30-metre resolution. Remote-sensing companies warn that there is insufficient commercial demand for such images, so the winning company may choose to use technology that can produce images of 10-metre resolution. These would be of interest to agricultural companies, as they can, for example, be used to monitor crops. But it is unclear whether this extra market will be enough to make a commercial Landsat profitable.

Without additional business, many Landsat users worry that the contractor will resort to high prices as a way to make ends meet. Ray Williamson, a remote-sensing policy expert at George Washington University in Washington DC, doubts that a commercial vendor can beat the current price of Landsat 7 images, and says that commercial clients are right to be concerned about the future.

If privatization fails again, some fear that

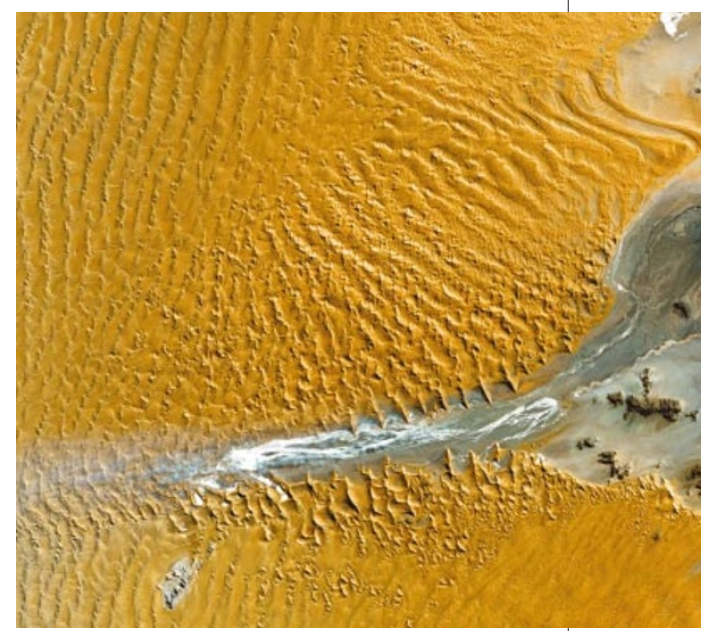

Eye in the sky: Landsat images, such as this one of sand dunes in the Namib Desert, are a rich source of data for global-change researchers.

the government could abandon its investment in Landsat altogether. Samuel Goward, a remote-sensing expert at the University of Maryland in College Park and chair of the Landsat science team, says that Congress has been very clear that it wants the next satellite to be commercially owned. "If there isn't a business involvement, the mission itself may disappear," he says.

\section{Ocean geologists hatch plan to probe ancient zone}

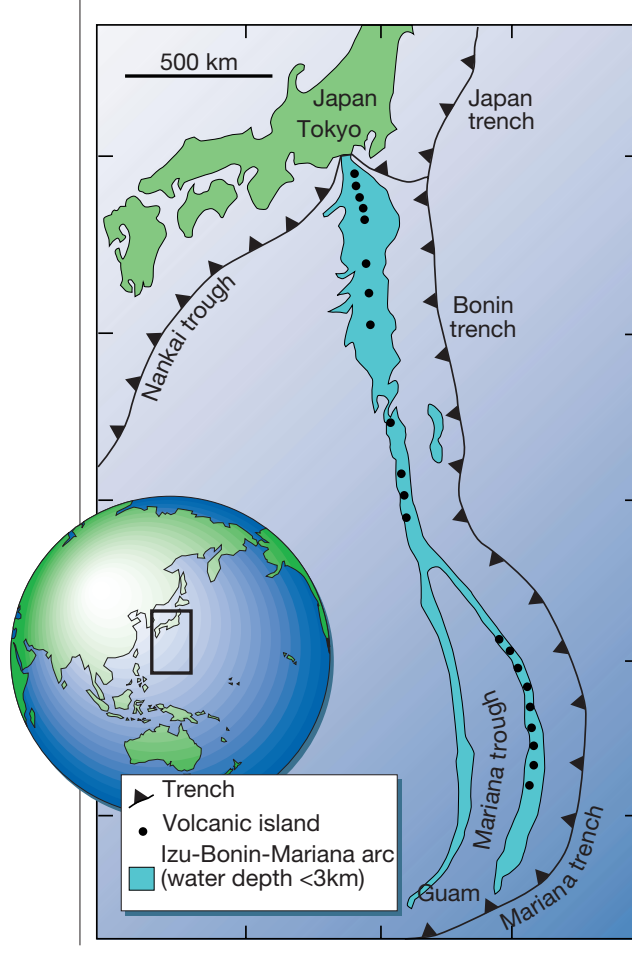

David Cyranoski, Tokyo

US and Japanese geologists are planning a major investigation of the Izu-Bonin-

Mariana Arc, a 2,800-kilometre subduction zone located in the Pacific Ocean south of Japan. Studying the region, where one oceanic plate is sliding underneath another, could shed light on many geological process, including how the first continents formed. "This collaboration will be one of the most concentrated geoscientific efforts over the next ten years," says Jim Gill, a geologist at the University of California, Santa Cruz.

Japanese researchers will have racked up seven one-month research missions to the area by the end of the year, and the US National Science Foundation (NSF) has invested \$4.5 million in studies there over the past few years. At a meeting held in Hawaii earlier this month by the NSF and Japan's Institute for Frontier Research on Earth Evolution, researchers outlined their plans for the coming decade.

Studies of the arc have been prioritized by the NSF and various Japanese research institutes, partly because the crust over oceanic plates is thinner than the continental crust, making it easier to obtain information from seismological signals. The relatively old age of the plate, which has been undergoing subduction for $\mathbf{4 3}$ million years, is a further incentive. Some researchers believe that the first continents were created in similar oceanic subduction zones. "It is the closest thing to how our continents got started some 3-4 billion years ago," says Gill.

At the Hawaii meeting, experiments to conducted with Chikyu, a new oceandrilling ship that is due to enter operation in 2006 (see Nature 415, 356; 2002), were cited as central to future studies. Geologists want to use the vessel's 7-kilometre drilling capacity to sample directly the composition of the crust and underlying mantle.

Time on Chikyu will be in short supply, however, as other groups are competing for time on the vessel. A single drilling mission takes around a year, so trips will be limited. A smaller collaboration is also bidding to use Chikyu to explore a subduction zone under the Aleutian Islands off the coast of Alaska. 